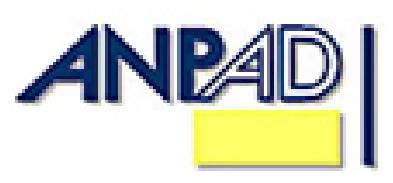

Disponível em

http://www.anpad.org.br/rac

RAC, Curitiba, v. 15, n. 1, art. 2,

pp. 25-46, Jan./Fev. 2011

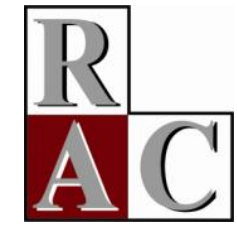

\title{
Relacionamentos Interorganizacionais e Resultados: Estudo em uma Rede de Cooperação Horizontal da Região Central do Paraná
}

\section{Interorganizational Relationships and Results: a Study in a Network of Horizontal Cooperation of the Central Region of Paraná}

Marcos de Castro * E-mail: mcastro@unicentro.br Universidade Estadual do Centro-Oeste Guarapuava, PR, Brasil.

Sergio Bulgacov

E-mail: s.bulgacov@gmail.com Universidade Federal do Paraná - PPGADM/UFPR Curitiba, PR, Brasil.

Valmir Emil Hoffmann E-mail: ehoffmann@unb.br Universidade de Brasília - FACE/UnB Brasília, DF, Brasil. permitido citar parte de artigos sem autorização prévia, desde que seja identificada a fonte. 


\title{
Resumo
}

A partir de uma lacuna evidenciada na literatura, esta pesquisa tem por objetivo analisar os resultados gerados por uma rede interorganizacional de cooperação do segmento varejista de materiais de construção. Para tanto, buscou-se primeiramente compreender os seus motivadores, bem como os dificultadores e facilitadores, para levantar em seguida os seus resultados e verificar de que forma estes se relacionam com aqueles fatores: motivadores, facilitadores e dificultadores e sua relação com os resultados dos relacionamentos constituem o eixo central na discussão apresentada no referencial teórico. O estudo de caso se mostrou a estratégia mais indicada para esta pesquisa descritiva, pois sua flexibilidade permitiu a combinação de métodos qualitativos e quantitativos. As evidências indicam que o principal dificultador foi o baixo nível de cooperação e a alta competição entre as empresas participantes. No que tange aos resultados dos relacionamentos, constata-se que os fatores motivadores não encontram correspondência, quando em confronto com os resultados dos relacionamentos. Evidencia-se, ainda, aparente correlação positiva entre o fator dificultador relacionado à cooperação e à competição com o fato das ações da associação não produzirem os efeitos esperados.

Palavras-chave: relacionamentos interorganizacionais; redes interorganizacionais; motivadores; facilitadores e dificultadores de redes; pequenas e médias empresas.

\begin{abstract}
Due to a gap in the literature, the objective of the present study is to understand the results of an interorganizational cooperation network in the retail segment of building materials. With this purpose, the motivating factors were first identified, in addition to the facilitating and complicating factors in order to achieve results and identify how they relate to these factors, and these factors and their link with the results of relationships are the center of the discussion presented in the literature review. The case study was regarded as the most effective strategy for this descriptive research since its inherent flexibility allowed both for a combination of qualitative and quantitative methods. It was seen that the main difficulty mentioned was the low level of cooperation and the high levels of competitiveness among the companies that were members of the association. In turn, concerning the results of the relationships, it was certified that the relationship motivators do not correspond with the results of such relationships. The study also demonstrates an apparent positive correlation between the complicating factor related to cooperation and competition with the fact that the association's actions do not produce the desired effect.
\end{abstract}

Key words: interorganizational relationships; interorganizational networks; motivators; facilitators and complicating factors to networks; small and medium firms. 


\section{Introdução}

O tema dos relacionamentos interorganizacionais tem sido, há algumas décadas, foco de vários estudos na teoria organizacional em outros países, principalmente na Europa e nos Estados Unidos. No contexto brasileiro, o interesse por esse tema ainda pode ser considerado recente e, apesar da crescente atenção a ele dispensada, o seu desenvolvimento teórico ainda não parece ocorrer de modo significativo, além de os estudos estarem concentrados no Sul do país, como mostraram Balestrin, Verschoore e Reyes (2010). O aumento dos estudos concernentes aos relacionamentos interorganizacionais talvez encontre justificativa na constatação empírica de que as organizações necessitem interagir com o seu ambiente para acessar os recursos necessários às suas atividades (Aldrich, 1979). No contexto das redes, essa forma de organização pode representar uma maneira eficaz para o alcance de objetivos individuais e coletivos, por meio de um complexo ordenamento de conexões, em que as organizações estabelecem inter-relações sob diferentes maneiras, em distintos contextos e a partir de expressões culturais diversas (Castells, 1999).

Oliver e Ebers (1998) destacam a importância de se verificar os motivos da formação e da manutenção dos relacionamentos no contexto das redes, sendo fundamental analisar as suas consequências. Considerando que toda e qualquer organização é constituída visando ao alcance de determinados objetivos, torna-se imperativo o acompanhamento dos seus resultados, pois nenhuma organização, mesmo as redes interorganizacionais, pode abrir mão de avaliar seus resultados (Wegner \& Dahmer, 2004). É nesse sentido que a preocupação central desse estudo reside nos resultados dos relacionamentos interorganizacionais, isto é, nas consequências advindas dos contatos entre organizações. No entanto, para melhor entendimento, primeiramente é necessário compreender quais são as expectativas que deram origem ao relacionamento.

Dessa forma, o entendimento e a avaliação dos resultados passam pela compreensão do que se busca, ao estabelecer os relacionamentos, aqui chamados de motivadores. Além disso, torna-se importante considerar que os resultados dos relacionamentos são afetados por fatores que podem inibir a formação e a manutenção das ligações, o que pode prejudicar o próprio relacionamento e, consequentemente, os seus resultados.

Diante dessas argumentações, o objetivo deste trabalho se assenta em avaliar os resultados dos relacionamentos interorganizacionais por meio da investigação em rede de cooperação, tendo como campo de estudo a Associação dos Comerciantes de Materiais de Construção da Região de Guarapuava, Acomac-Guarapuava. Para tanto, buscou-se primeiramente compreender os motivadores, os dificultadores e facilitadores da rede; para então, levantar os seus resultados; e verificar de que forma estes se relacionam com aqueles fatores. Quanto a sua estrutura, o texto se inicia com esta introdução ao objetivo de pesquisa. Na sequência têm-se o referencial teórico, os procedimentos metodológicos adotados, a apresentação e análise dos dados, a conclusão e as referências bibliográficas utilizadas.

\section{Referencial Teórico}

O referencial teórico está ordenado de forma que se discute primeiro os aspectos que motivam os relacionamentos interorganizacionais, em seguida os fatores que facilitam ou dificultam a formação e manutenção desses relacionamentos e, por fim, ressaltam-se os seus resultados.

\section{Motivadores dos relacionamentos interorganizacionais}

A questão inicial do trabalho decorre da literatura sobre os motivadores dos relacionamentos: por quais motivos e dentro de quais condições as organizações estabelecem ligações com outras 
organizações? Consideram-se como relacionamento interorganizacional as transações, os fluxos e ligações de recursos relativamente duradouros que ocorrem entre duas ou mais organizações (Oliver, 1990); a sua existência pressupõe um processo de escolha do grupo de interação daqueles que são relevantes no conjunto de organizações (Cunha, 2004; Fiedler \& Welpe, 2010).

Uma parcela da literatura entende que os relacionamentos interorganizacionais são, inicialmente, motivados pela busca de eficiência e podem ser vistos como forma de negociação, na qual cada organização procura maximizar sua vantagem na obtenção e na alocação de recursos que são fundamentais para sua sobrevivência (Franco, 2007; Hall, 2004; Oliver, 1990). Whetten e Leung (1979) chamam a atenção para o fato de que uma organização pode estabelecer relações interorganizacionais devido ao seu valor instrumental, isto é, eles consideram o grau com que uma dada ligação poderá contribuir para o alcance dos objetivos organizacionais. Dessa forma, a procura da eficiência enfatiza a importância da obtenção de recursos para as organizações envolvidas, o que implica racionalidade, à medida que as organizações procuram maximizar seus ganhos na interação (Oliver, 1990; Whetten \& Leung, 1979).

O poder também é citado como motivador dos relacionamentos interorganizacionais, em função do potencial que determinado relacionamento tem de permitir a uma organização praticá-lo sobre suas congêneres ou sobre seus recursos (Aldrich, 1979; Oliver, 1990; Papadopoulos, Cimon, \& Hébert, 2008). Ao abordar o poder para explicar os relacionamentos interorganizacionais, sugere-se que a escassez de recursos motiva as organizações a tentar exercer poder, influência ou controle sobre outras que possuem os recursos requeridos, contrastando com o pressuposto de que a escassez de recursos motiva as organizações a cooperarem entre si. Whetten e Leung (1979) acrescentam que a decisão de interagir com outra organização pode ser motivada em função do aumento que tal relação poderá trazer ao poder pessoal dos dirigentes.

Em contraste com o poder, parte da literatura assume que os relacionamentos são motivados pela necessidade de cooperação interorganizacional. Contudo, Oliver (1990) chama a atenção para o fato de que poucos estudos contrastam o poder e a cooperação, pois a escassez de recursos pode tanto induzir à cooperação (Franco, 2007; Mellat-Parast \& Digman, 2008; Ottone \& Ponzano, 2010; Schermerhorn, 1975) quanto à competição (Gnyawali \& Madhavan, 2001; Ottone \& Ponzano, 2010).

As organizações também estabelecem relacionamentos interorganizacionais como forma de tornarem-se mais estáveis em face das incertezas ambientais, ou seja, elas se utilizam dos relacionamentos como resposta adaptativa ao ambiente incerto. A incerteza ambiental é gerada pela escassez de recursos, que motiva as organizações a estabelecer relacionamentos para alcançar estabilidade e previsibilidade nas relações com outras organizações (Brass, Galaskiewicz, Greve, \& Tsai, 2004; Galaskiewicz, 1985; Whetten \& Leung, 1979).

\section{Fatores facilitadores e dificultadores dos relacionamentos interorganizacionais}

Para a compreensão dos motivadores e dos resultados é necessário também entender os fatores facilitadores e dificultadores dos relacionamentos interorganizacionais. Tais fatores são representados por aspectos ambientais e organizacionais que estimulam ou inibem determinado relacionamento, ou seja, influenciam a sua formação e manutenção (Candido \& Abreu, 2004; Oliver, 1990). Também podem ser explicados como aqueles que induzem à ocorrência dos relacionamentos interorganizacionais, representando pré-condições ou antecedentes para as interações (Hall, 2004).

A criação de confiança entre os parceiros é, certamente, um dos fatores mais citados na literatura, e é considerada pré-requisito para a cooperação (Hakansson, Kjellberg, \& Lundgren, 1992; Hoffmann \& Scholosser, 2001; Mellat-Parast \& Digman, 2008). A confiança se apresenta como algo a ser construído ao longo do tempo (Jarillo \& Stevenson, 1991; Park \& Jungson, 2001), pois as características básicas, como honestidade, disposição e eficácia podem ser percebidas apenas ao longo do tempo (Lajara, Lillo, \& Sempere, 2002). Na visão de Hoffmann e Schlosser (2001), a confiança pode ser construída desde o período inicial das negociações para a formação da rede, dependendo da demonstração entre os parceiros, do compromisso futuro de investimentos comuns, do 
compartilhamento de informações e da utilização de salvaguardas (Dyer, 1996). Assim como, quando um parceiro percebe que o outro lhe atribui confiança, é mais fácil a criação de um ciclo de construção de confiança (Thoben \& Jagdev, 2001). Como pontuam Verschoore e Balestrin (2008), a confiança é um produto das relações sociais que se estabelecem a partir da criação das redes de cooperação, pois elas aproximam os agentes e, dessa forma, as relações acabam extrapolando o plano econômico. Por outro lado, Brusco (1993) afirma que a confiança está conectada com a cooperação e ambas são favorecidas em termos de vínculos econômicos, quando existem vínculos sociais anteriores, como é o caso das aglomerações de empresas. Juntamente com a confiança, o comprometimento é citado como um dos mais importantes fatores para a formação e manutenção do relacionamento interorganizacional (Isabella, 2002). Quando o parceiro é comprometido com o relacionamento, irá despender esforços para que este tenha sucesso. A literatura indica que o participante que não se compromete com a relação tende a agir de maneira oportunista, deixando que o parceiro se responsabilize por todo o esforço e investimento para desenvolvimento da relação (Medcof, 1997), e pode controlar negativamente o relacionamento (Hakansson \& Ford, 2002). O comprometimento traduz-se em lealdade com os parceiros, sendo considerado um fator influenciador do sucesso do relacionamento (Koza \& Lewin, 2000).

A dinâmica existente nas redes interorganizacionais tem sido apresentada pela literatura como produto de uma série de aspectos que reúnem em si a cooperação e a competição. A literatura sobre competição tem relatado interações entre organizações concorrentes que cooperam entre si para alcançar objetivos comuns, de maneira que se assume o pressuposto de que o estabelecimento de relacionamentos cooperativos influencia o comportamento competitivo das organizações (Gimeno, 2004; Gnyawali \& Madhavan, 2001; Reinl \& Kelliher, 2010). Balestrin e Vargas (2004) acrescentam que a confiança e a cooperação ocorrem simultaneamente com a competição e são diretamente influenciadas pelos aspectos estruturais das redes interorganizacionais. Dessa forma, Loiola e Moura (1996) destacam que as formas interorganizacionais cooperativas são estruturas que privilegiam as relações de parceria sem, no entanto, eliminar a competição e os conflitos.

\section{Resultados dos relacionamentos interorganizacionais}

Ao estudar as ações das organizações em um contexto de estratégia, torna-se importante compreender como as suas ações impactam seus resultados. No caso das redes, a literatura tem indicado que as organizações que participam de relacionamentos interorganizacionais cooperativos obtêm melhores resultados do que aquelas que não atuam dessa forma (e. g. Human \& Provan, 1997; Mellat-Parast \& Digman, 2008). Ocorre que os seus benefícios e resultados são difíceis e complexos de avaliar (Fryxel, Dooley, \& Vryza, 2002; Gulati, 1998; Human \& Provan, 1997), pois tanto indivíduos quanto organizações são afetados por esses resultados (Hall, 2004). Embora possa parecer simples, de acordo com o ponto de vista do observador, indivíduos diferentes podem ter concepções distintas de tais resultados (Provan \& Milward, 1995). Nesse sentido, as consequências dos relacionamentos interorganizacionais podem ser avaliadas por observadores internos ou externos da organização, de maneira que concepções conflitantes demandem conciliação diante dessa problemática. De acordo com Oliver e Ebers (1998), poucos trabalhos se propõem a estudar as consequências dos relacionamentos interorganizacionais. Esses autores identificaram que não existe claro consenso na literatura sobre os seus resultados, de forma que os estudos se têm concentrado sobre poucos e diferentes tipos de implicações, o que dificulta a comparação dos achados e, consequentemente, compromete o completo entendimento dos resultados dos relacionamentos. Heimeriks e Shreiner (2002) acrescentam que tais pesquisas têm produzido poucas contribuições para a literatura em função da dificuldade em identificar construtos que possam mensurar tais resultados.

Considerando que as organizações utilizam os seus relacionamentos para alcançar objetivos estratégicos, os resultados podem ser mensurados em termos do alcance dos objetivos individuais (Parkhe, 1993; Yan \& Gray, 1994). Pereira (2005) ressalta que a vantagem de enfocar as organizações individualmente realça que a rede de relacionamento é constituída de tais organizações, e os resultados desses relacionamentos dependem dos resultados das organizações que constituem a rede. $\mathrm{O}$ autor acrescenta que o ganho econômico advindo da organização individual oferece a base para qualquer 
estratégia cooperativa. Além disso, os resultados dos relacionamentos podem ser avaliados em termos do alcance dos objetivos esperados pelo grupo, na formação de tais interações (Geringer \& Hebert, 1989). Diante disso, tem-se que a problemática da avaliação dos resultados dos relacionamentos interorganizacionais exige análise que considere a existência de um contexto em que a individualidade das organizações convive com a coletividade dos relacionamentos. Não apenas as organizações que participam dos relacionamentos necessitam avaliar seus resultados, como também a própria rede precisa ser avaliada, considerando que as duas dimensões se relacionam e se modificam mutuamente.

Entre outros aspectos, deve-se considerar que, embora haja um resultado coletivo, as organizações participantes se mantêm autônomas e sem vínculos financeiros; normalmente não existem mensurações contábeis para o conjunto da rede, mas exclusivamente para as organizações consideradas individualmente. Embora a participação nos relacionamentos sempre tenha por objetivo o benefício econômico final, a medida do resultado dos relacionamentos também precisa envolver fatores qualitativos, como coesão do grupo, capacidade de análise estratégica, capacidade de planejamento e intensidade de cooperação e competição (Wegner \& Dahmer, 2004). Ou, em outras palavras, análises organizacionais carecem da consideração de variáveis que transcendem os limites atrelados aos cálculos de eficiência, competência, produtividade entre tantos outros, conforme Machado-da-Silva e Coser (2006).

Considera-se que o escopo das redes é a obtenção de melhores resultados globais para o conjunto de organizações e não para cada uma individualmente. Isso equivale a dizer que, embora a avaliação individual das organizações seja importante, a eficiência coletiva também tem papel de destaque (Wegner \& Dahmer, 2004).

Em consequência da necessidade de mensuração dos resultados, surge a preocupação de encontrar indicadores e formas de avaliação adequadas, que permitam comparar os resultados esperados com os alcançados pelas redes interorganizacionais. Considerando que as duas dimensões de resultados não são excludentes, torna-se imperativo que elas sejam integradas para essa avaliação.

Como opção às medidas objetivas de resultado, a literatura tem utilizado medidas subjetivas (Dess \& Robinson, 1984), que parecem convenientes para pesquisas que encontram dificuldades com relação às objetivas. Ao medir os resultados subjetivamente, a fonte passa a ser a percepção das pessoas envolvidas nos relacionamentos sobre a evolução ou involução dos indicadores utilizados, ou então sobre a contribuição dos relacionamentos para o alcance de determinados objetivos, sejam eles individuais, coletivos, econômicos ou não-econômicos.

Dentro dessa concepção, Pereira (2005) acrescenta que uma forma popular, porém menos explícita, de analisar o resultado dos relacionamentos é mensurá-lo em termos de satisfação das organizações para com os relacionamentos, de forma que essa medida tem sido uma das mais utilizadas para avaliar tais resultados (e. g. Ariño, 2003; Beamish, 1987; Dess \& Robinson, 1984; Fryxel et al., 2002; Human \& Provan, 1997; Parkhe, 1993; Pereira, 2005).

\section{Procedimentos Metodológicos}

Diante do objetivo proposto, esta pesquisa classifica-se como descritiva de acordo com os preceitos de Godoy (1995b). A estratégia de pesquisa adotada foi o estudo de caso. Essa opção se justifica em função da profundidade e flexibilidade que é inerente a essa estratégia (Eisenhardt, 1989; Godoy, 1995b).

O modelo teórico da pesquisa é composto por duas categorias independentes representadas pelos fatores motivadores, isto é, expectativas quanto ao relacionamento; pelos fatores facilitadores e dificultadores, os quais agem sobre a formação e manutenção da rede interorganizacional, âmbito de análise interorganizacional; na participação dos integrantes da rede, âmbito de análise organizacional; e uma categoria dependente representada pelos resultados dos relacionamentos. Cabe destacar que, 
apesar de não fazer parte dos objetivos desta pesquisa, na representação das categorias de análise considera-se a ação das características da rede como elemento que afeta os resultados dos relacionamentos interorganizacionais (RIOs), conforme a Figura 1.

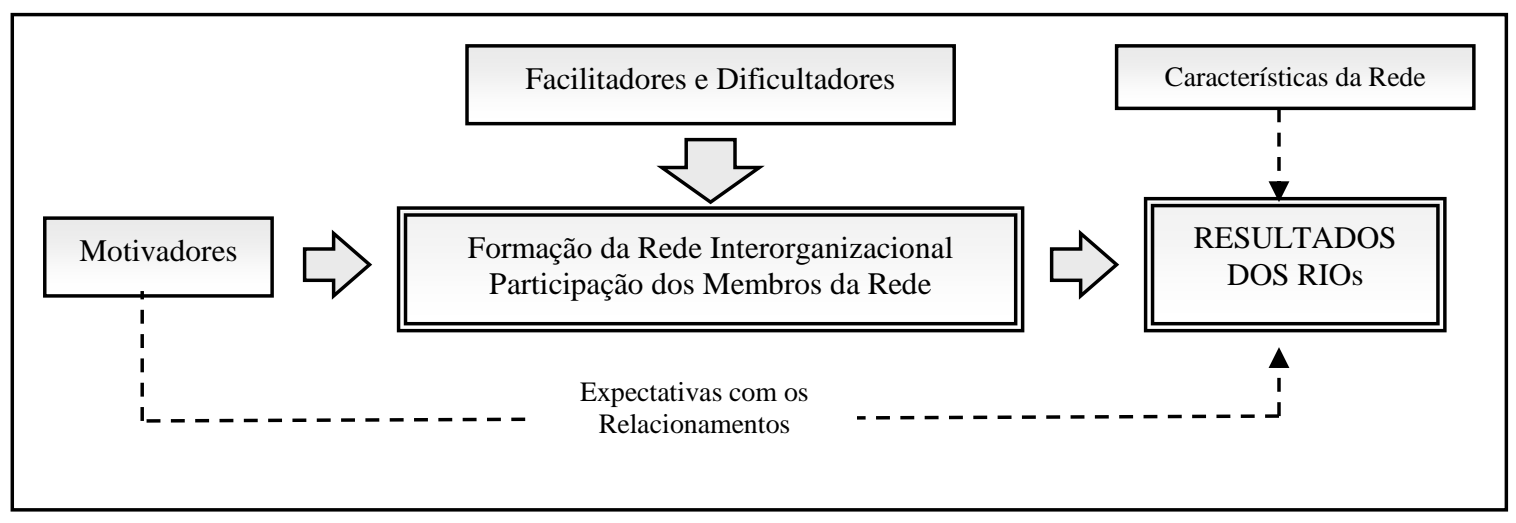

Figura 1. Modelo Teórico da Pesquisa.

A escolha do caso estudado se deu, considerando o tipo de relacionamento existente (formal do tipo horizontal); a idade da rede (mais de cinco anos); número de participantes (acima de 30); localização e, ainda, acessibilidade do pesquisador.

Para a escolha de quais organizações integrantes da rede de relacionamentos seriam abordadas na pesquisa, utilizou-se o critério de amostragem não-probabilístico intencional para selecionar as organizações que fizeram parte da primeira fase da pesquisa. Isso se justifica por ser o método de amostragem mais indicado para uma situação que exige a seleção de um pequeno número da população, produzindo amostra mais significativa e representativa que uma amostra probabilística (Richardson, 1989). Para a segunda fase da pesquisa, foi utilizado o critério amostral não-probabilístico por conveniência, pois permitiu que as organizações a serem pesquisadas fossem selecionadas em função da sua acessibilidade (Richardson, 1989).

No que concerne à coleta de dados, a pesquisa fez uso de dados primários e secundários em duas fases. A primeira fase foi de caráter qualitativo, de forma que os dados foram obtidos por meio de entrevistas com roteiro semiestruturado com os proprietários ou gerentes de 10 empresas participantes e com 2 dirigentes da Acomac-Guarapuava, Associação dos Comerciantes de Materiais de Construção da Região de Guarapuava. Cada entrevista teve duração entre 50 a 60 minutos e o número de entrevistas com proprietários e gerentes foi definido por meio do critério de saturação dos dados (Flick, 2004). Nessa fase, também foi utilizada a pesquisa documental, que foi realizada utilizando-se documentos, tanto impressos quanto eletrônicos, tais como sítios na internet; estatuto da Acomac-Guarapuava; cadastros dos associados fornecidos pela Acomac-Guarapuava; boletins informativos trimestrais da Acomac-Guarapuava; revistas especializadas do setor (Revista da Federação dos Comerciantes de Materiais de Construção do Paraná, Revista da Associação Nacional dos Comerciantes de Materiais de Construção); e dados de órgãos oficiais.

Como sugere Eisenhardt (1989) e, a exemplo de Human e Provan (1997), com os dados colhidos na primeira fase e, com apoio do referencial teórico, elaborou-se o instrumento ou questionário estruturado utilizado na segunda fase da pesquisa. O questionário utilizou uma escala de cinco pontos e foi aplicado junto aos responsáveis por cada uma das organizações selecionadas para o estudo. O número de questionários coletados nessa fase da pesquisa foi de 42 , porém somente 37 puderam ser validados.

A análise de dados compreendeu três fases: (a) análise das entrevistas e documentos; (b) análise dos questionários estruturados; e (c) verificação de padrões convergentes entre as evidências coletadas por meio da triangulação dos dados obtidos na primeira e segunda fase.

Com relação à primeira fase da análise, as entrevistas gravadas foram transcritas e submetidas, juntamente com os outros documentos, à técnica de análise qualitativa de conteúdo (Flick, 2004; Laville 
\& Dionne, 1999). Considerando que a pesquisa qualitativa "parte de questões ou focos de interesses amplos, que se vão definindo à medida que o estudo se desenvolve" (Godoy, 1995a, p. 58), a construção das categorias de análise utilizou um modelo do tipo misto (Laville \& Dionne, 1999).

No que diz respeito à segunda fase da análise de dados, foram utilizadas as seguintes técnicas estatísticas: distribuição de frequência, medidas de tendência central, tabulações cruzadas, análise fatorial, análise de cluster, técnicas de comparação de amostras e testes de correlação.

Por fim, na terceira fase de análise, foi utilizada a técnica da triangulação dos dados, comparandose os dados das entrevistas semiestruturadas, dos documentos e dos questionários de forma a identificar e caracterizar padrões convergentes entre os resultados (Flick, 2004; Laville \& Dionne, 1999).

\section{Apresentação dos Dados}

Os dados serão apresentados a partir da ordem estabelecida pelo modelo teórico: motivadores dos relacionamentos; facilitadores ou dificultadores dos relacionamentos e por fim os resultados dos relacionamentos.

\section{Motivadores dos relacionamentos interorganizacionais}

Para identificar os motivadores presentes na formação da Acomac-Guarapuava, os dirigentes da associação foram questionados sobre quais os objetivos que levaram à formação daquela associação. Assim, surgiram três categorias que orientaram o processo de análise: (a) melhoria dos relacionamentos com empresas do setor; (b) acesso a recursos; e (c) melhoria do relacionamento com fornecedores.

Para a fase quantitativa da pesquisa, os motivadores dos relacionamentos interorganizacionais foram considerados apenas com relação à participação dos associados na Acomac-Guarapuava.

Por meio da técnica de análise fatorial (Tabela 1), foram identificados quatro fatores para os motivadores dos relacionamentos interorganizacionais denominados Relacionamentos e Proteção (Fator 1); Busca de Competitividade e Atingimento de Objetivos (Fator 2); Conhecimentos (Fator 3); e Combate à Venda Direta (Fator 4). A análise apresentou um KMO =0,720 e Teste de esfericidade de Bartlett $=366,675$ com significância $=0,000$. Para a verificação da confiabilidade das escalas foi utilizado o alfa de Cronbach, cujos resultados também estão na Tabela 1 e atestam a aceitabilidade das escalas, conforme adotado por Hair, Anderson, Tatham e Black (2005). Considerando que o fator 4 é composto de apenas um indicador, não foi possível calcular a sua confiabilidade, porém destaca-se que a sua carga fatorial pode ser considerada alta $(0,88)$. Além disso, este fator apresenta-se como relevante para a pesquisa.

Tabela 1

\section{Motivadores dos Relacionamentos}

\begin{tabular}{|c|c|c|c|c|}
\hline & \multicolumn{4}{|c|}{ Fatores } \\
\hline & 1 & 2 & 3 & 4 \\
\hline Melhorar o relacionamento com os fornecedores & ,854 & & & \\
\hline Obter contato com novos fornecedores & 837 & & & \\
\hline Fortalecer a minha empresa tornando-a mais estável contra possíveis crises do setor & ,802 & & & \\
\hline Ter acesso a linhas de crédito mais vantajosas para a empresa &, 779 & & & \\
\hline
\end{tabular}




\section{Tabela 1 (continuação)}

\begin{tabular}{|c|c|c|c|c|}
\hline & \multicolumn{4}{|c|}{ Fatores } \\
\hline & 1 & 2 & 3 & 4 \\
\hline Poder realizar parcerias com outras empresas do setor & ,726 & & & \\
\hline $\begin{array}{l}\text { Melhorar a comunicação da minha empresa com os outros associados, trocando } \\
\text { informações, discutindo problemas comuns e compartilhar as melhores práticas }\end{array}$ & ,713 & & & \\
\hline $\begin{array}{l}\text { Reconhecer que a cooperação entre as lojas de materiais de construção pode contribuir para } \\
\text { o crescimento mútuo das empresas do setor }\end{array}$ & 643 & & & \\
\hline $\begin{array}{l}\text { Considerar que ela poderia contribuir para a melhoria dos resultados financeiros da minha } \\
\text { empresa (vendas, lucratividade, faturamento) }\end{array}$ & & ,906 & & \\
\hline $\begin{array}{l}\text { Melhorar o desempenho operacional da minha empresa (qualidade dos produtos } \\
\text { comercializados, introdução de novos produtos) }\end{array}$ & &, 855 & & \\
\hline Considerar que ela poderia contribuir para o alcance dos objetivos de minha empresa & & ,709 & & \\
\hline Ganhar competitividade em comparação aos concorrentes que não fazem parte da Acomac & & ,632 & & \\
\hline Ter acesso a novos conhecimentos e, assim, melhorar as minhas habilidades de gestão & & & ,802 & \\
\hline $\begin{array}{l}\text { Participar, juntamente com meus funcionários, dos treinamentos, palestras e cursos } \\
\text { oferecidos pela Acomac }\end{array}$ & & & ,721 & \\
\hline Ter acesso às informações divulgadas pela Acomac & & & 617 & \\
\hline Colaborar para o combate à venda direta sem critérios por parte da indústria & & & &, 880 \\
\hline Variância Explicada & $32,6 \%$ & $19,5 \%$ & $14,3 \%$ & $10,9 \%$ \\
\hline Variância Acumulada & $32,6 \%$ & $52,1 \%$ & $66,4 \%$ & $77,3 \%$ \\
\hline Alfa de Cronbach & ,902 & ,836 &, 721 & - \\
\hline
\end{tabular}

O Fator 1 relacionamentos e proteção revela a expectativa por estabelecer contatos que promovam benefícios individuais e coletivos para as empresas do setor. O Fator 2 competitividade e atingimento dos objetivos assenta-se principalmente no desempenho individual da organização, pois os respondentes demonstram que a sua participação na Acomac-Guarapuava foi motivada pela melhoria do desempenho financeiro e operacional, melhoria da competitividade e alcance de outros objetivos de sua organização. Já, o Fator 3 conhecimentos evidencia a importância dada pelos respondentes aos aspectos relacionados à aprendizagem como fruto de maior interação das empresas do setor de materiais de construção daquela região, o que permitiria a troca de conhecimentos, bem como compartilhar problemas comuns. Por sua vez, o Fator 4 referente ao combate à venda direta apresenta carga fatorial considerada elevada, representando a preocupação dos respondentes com a ação dos fabricantes que vendem diretamente ao consumidor final.

Após os procedimentos de validação das escalas, o construto motivadores dos relacionamentos interorganizacionais foi submetido à técnica de Análise de cluster (Tabela 2). Considerando os quatro fatores apontados pela análise fatorial, foram encontrados dois grupos homogêneos internamente e heterogêneos entre si. O teste U de Mann-Whitney (Bisquerra, Sarriera, \& Martinez, 2004; Malhotra, 2001 ) aponta diferenças estatisticamente significantes ( $p$-value $=0,000$, em nível de significância de $95 \%$ ) para três dos fatores motivadores dos relacionamentos entre os dois grupos originados na análise de cluster. Somente o fator "colaborar para o combate à venda direta sem critérios por parte da indústria" não apresentou diferenças entre os dois grupos ( $p$-value $=0,764$, em nível de significância de $95 \%)$. 
Tabela 2

Comparação dos Grupos para Fatores Motivadores dos Relacionamentos

\begin{tabular}{|c|c|c|c|c|}
\hline & $\begin{array}{l}\text { Relacionamento e } \\
\text { Proteção }\end{array}$ & $\begin{array}{c}\text { Busca de } \\
\text { Competitividade e } \\
\text { Atingimento de } \\
\text { Objetivos }\end{array}$ & Conhecimentos & $\begin{array}{l}\text { Colaborar para o } \\
\text { combate à venda } \\
\text { direta sem critérios } \\
\text { por parte da indústria }\end{array}$ \\
\hline Mann-Whitney U & 29,500 & 41,000 & 34,500 & 154,500 \\
\hline Wilcoxon W & 134,500 & 146,000 & 139,500 & 259,500 \\
\hline $\mathrm{Z}$ & $-4,130$ & $-3,781$ & $-4,092$ &,- 300 \\
\hline Asymp. Sig. (2-tailed) &, 000 & 000 & 000 & ,764 \\
\hline Exact Sig. [2*(1-tailed Sig.)] &, 000 & 000 &, 000 &, 841 \\
\hline
\end{tabular}

\section{Facilitadores e dificultadores dos relacionamentos interorganizacionais}

A partir dos dados levantados na etapa qualitativa, identificaram-se duas categorias como sendo os principais facilitadores dos relacionamentos: (a) Participação de Outras Entidades; e a (b) Forma de Gestão da Associação. Por sua vez, o principal dificultador refere-se à intensidade de cooperação e competição nos relacionamentos.

Para a fase quantitativa da pesquisa, os respondentes foram questionados sobre quais fatores estariam facilitando ou dificultando a sua participação na Acomac-Guarapuava. A análise fatorial (Tabela 3) evidenciou dois fatores para os facilitadores e dificultadores dos relacionamentos interorganizacionais denominados Cooperação e Competição (fator 1); e Forma de Gestão da Associação (fator 2). Essa análise apresentou um KMO $=0,737$ e Teste de esfericidade de Bartlett $=187,386 \mathrm{com}$ significância $=0,000$. A confiabilidade das escalas foi verificada por meio do alfa de Cronbach. $O$ fator 1 "cooperação e competição" foi indicado pelos participantes da pesquisa como dificultador dos relacionamentos interorganizacionais entre os integrantes da Acomac-Guarapuava (média $=2,78$ e mediana $=2,85$ ). Por sua vez, o fator forma de gestão da associação (fator 2) não foi avaliado pelos participantes da pesquisa como dificultador para a participação na Acomac-Guarapuava (média = 3,34 e mediana =3,25).

Tabela 3

\section{Facilitadores e Dificultadores dos Relacionamentos}

\begin{tabular}{lc}
\hline & Fatores \\
\cline { 2 - 2 } O tipo de concorrência praticada pelos participantes da Acomac & 1 \\
A conscientização das empresas do setor sobre a importância da cooperação &, 852 \\
O nível de confiança entre os participantes da Acomac &, 802 \\
O nível de interação entre os participantes da Acomac &, 787 \\
A experiência dos participantes em cooperação &, 785 \\
O respeito existente entre os participantes da Acomac &, 705 \\
A comunicação entre os participantes da Acomac &, 651 \\
O tempo que o presidente da Acomac dedica à associação &, 605 \\
A forma com que a associação está sendo conduzida por seus dirigentes &, 862 \\
A frequência das reuniões com todos os associados &, 697 \\
\hline
\end{tabular}


Tabela 3 (continuação)

\begin{tabular}{lll}
\hline & \multicolumn{2}{c}{ Fatores } \\
\cline { 2 - 3 } & \multicolumn{1}{c}{1} & \multicolumn{1}{c}{2} \\
\hline A experiência do presidente da Acomac em cooperação & &, 623 \\
\hline Variância Explicada & $39,20 \%$ & $22,04 \%$ \\
Variância Acumulada & $39,20 \%$ & $61,24 \%$ \\
Alfa de Cronbach & 0,877 & 0,754 \\
\hline
\end{tabular}

\section{Resultados dos relacionamentos interorganizacionais}

A exemplo da fase qualitativa, a fase quantitativa também se deu, primeiramente, por meio da comparação entre o que era esperado (motivadores) e o que foi alcançado (resultados) na percepção daqueles dois clusters gerados no início da análise quantitativa. Dessa forma, agruparam-se os indicadores para os resultados dos relacionamentos interorganizacionais da mesma forma que foi apresentada pela análise fatorial (Tabela 4) dos motivadores dos relacionamentos, isto é, Relacionamentos e Proteção (Fator 1); Competitividade e Atingimento de Objetivos (Fator 2); Conhecimentos (Fator 3); Venda Direta (Fator 4).

Tabela 4

Comparação dos Clusters para os Resultados dos Relacionamentos

\begin{tabular}{lrrrr}
\hline & $\begin{array}{c}\text { Relacionamentos } \\
\text { e Proteção }\end{array}$ & $\begin{array}{c}\text { Competitividade } \\
\text { e Atingimento de } \\
\text { Objetivos }\end{array}$ & Conhecimentos & Venda Direta \\
\hline Mann-Whitney U & 89,000 & 119,500 & 133,000 & 103,500 \\
Wilcoxon W & 194,000 & 224,500 & 409,000 & 208,500 \\
Z & $-2,264$ & $-1,315$ &,- 934 & $-1,933$ \\
Asymp. Sig. (2-tailed) &, 024 &, 188 &, 350 &, 053 \\
Exact Sig. [2*(1-tailed Sig.)] &, 024 &, 196 &, 394 &, 071 \\
\hline
\end{tabular}

Por meio do teste U de Mann-Whitney realizou-se a comparação daqueles dois clusters com os quatro fatores citados anteriormente. Os resultados indicam haver diferenças apenas no fator relacionamentos e proteção $(p$-value $=0,024)$. Isso evidencia que o primeiro cluster não percebe influência positiva da Acomac-Guarapuava, em termos de relacionamentos e proteção (média = 2,69 e mediana $=2,64$ ). Para os outros três fatores, não foram encontradas diferenças estatisticamente significantes.

Considerando que os quatro fatores anteriores foram medidos primeiramente como motivadores e, posteriormente, na forma de resultados, realizou-se um comparativo entre os fatores do construto motivadores com o construto de resultado, na tentativa de verificar possíveis correlações entre eles. Por se tratar de variáveis não métricas medidas por meio de escalas ordinais, o teste mais indicado para esse fim é o coeficiente de correlação rho de Spearman ( $\rho s)$ (Bisquerra et al., 2004; Malhotra, 2001). Dessa forma, percebe-se na Tabela 5, que o fator motivador "relacionamentos e proteção" apresenta correlação positiva com os fatores de resultado denominados relacionamentos e proteção; competitividade e atingimento de objetivos; e, conhecimentos. O fator motivador competitividade e atingimento de objetivos apresenta correlação positiva apenas com o seu fator equivalente para resultado. $O$ fator motivador conhecimentos não apresentou correlação com nenhum dos fatores de resultado. Já o fator venda direta apresentou correlação positiva com o fator de resultado denominado conhecimentos. 
Tabela 5

Correlação de Spearman para Motivadores X Resultados

\begin{tabular}{|c|c|c|c|c|c|c|}
\hline & & & $\begin{array}{l}\text { Relacionamentos } \\
\text { e Proteção* }\end{array}$ & $\begin{array}{c}\text { Competitividade } \\
\text { e Atingimento de } \\
\text { Objetivos* }\end{array}$ & Conhecimentos* & $\begin{array}{l}\text { Venda } \\
\text { Direta* }\end{array}$ \\
\hline \multirow[t]{12}{*}{$\begin{array}{l}\text { Spearman's } \\
\text { rho }\end{array}$} & \multirow{3}{*}{$\begin{array}{l}\text { Relacionamento e } \\
\text { Proteção* }\end{array}$} & $\begin{array}{r}\text { Correlation } \\
\text { Coefficiente }(\rho s)\end{array}$ & ,407 &, 386 & ,371 &,- 247 \\
\hline & & Sig. (2-tailed) &, 012 & ,018 &, 024 & ,141 \\
\hline & & $\mathrm{N}$ & 37 & 37 & 37 & 37 \\
\hline & \multirow{3}{*}{$\begin{array}{c}\text { Busca de } \\
\text { Competitividade } \\
\text { e Atingimento de } \\
\text { Objetivos* }\end{array}$} & $\begin{array}{r}\text { Correlation } \\
\text { Coefficiente }(\rho s)\end{array}$ & ,277 &, 507 & ,205 &,- 226 \\
\hline & & Sig. (2-tailed) & ,097 &, 001 & ,224 &, 179 \\
\hline & & $\mathrm{N}$ & 37 & 37 & 37 & 37 \\
\hline & \multirow{3}{*}{ Conhecimentos* } & $\begin{array}{r}\text { Correlation } \\
\text { Coefficiente }(\rho s)\end{array}$ &,- 139 &, 035 & ,122 &,- 048 \\
\hline & & Sig. (2-tailed) &, 410 &, 836 & ,472 & ,777 \\
\hline & & $\mathrm{N}$ & 37 & 37 & 37 & 37 \\
\hline & \multirow{3}{*}{$\begin{array}{c}\text { Combate à Venda } \\
\text { Direta }\end{array}$} & $\begin{array}{r}\text { Correlation } \\
\text { Coefficiente }(\rho s)\end{array}$ & ,136 &,- 033 & ,490 &,- 260 \\
\hline & & Sig. (2-tailed) & ,422 &, 844 & ,002 &, 120 \\
\hline & & $\mathrm{N}$ & 37 & 37 & 37 & 37 \\
\hline
\end{tabular}

Nota. *Os fatores constantes da primeira linha referem-se aos resultados e os fatores da segunda coluna referem-se aos motivadores.

Analisando-se isoladamente o construto resultados dos relacionamentos, tem-se um KMO = 0,708 e Teste de esfericidade de Bartlett $=347,948$ com significância $=0,000$. Foram identificados cinco fatores (Tabela 6) para os motivadores dos relacionamentos interorganizacionais: Relacionamentos Horizontais e Atingimento de Objetivos (Fator 1); Desempenho e Acesso a Recursos Financeiros (fator 2); Relacionamentos com Fornecedores (Fator 3); Conhecimentos (Fator 4); e, Venda Direta (Fator 5). A verificação da confiabilidade foi feita por meio do alfa de Cronbach. Da mesma forma que o construto motivadores, o indicador referente à venda direta foi mantido isolado, $\mathrm{e}$ formou um único fator, em função da sua alta carga fatorial e da sua importância para o estudo.

O Fator 1, (média=2,90; mediana $=2,80$ ) revela que os respondentes não perceberam influência da Acomac-Guarapuava nos relacionamentos entre as empresas do setor como se esperava. $\mathrm{O}$ fator 2 (média $=2,85$; mediana $=2,60$ ) assenta-se principalmente no desempenho individual da organização e no acesso a recursos. Quanto ao Fator 3 (média $=2,82$; mediana $=3,00$ ) nota-se que os respondentes não têm certeza da influência da Acomac-Guarapuava na melhoria dos relacionamentos com fornecedores e no contato com novos fornecedores. O Fator 4 (média $=3,69$; mediana $=4,00$ ) demonstra que os respondentes parecem avaliar positivamente a influência da Acomac-Guarapuava, em termos de conhecimentos para sua organização, pois eles percebem que a associação permitiu o acesso a conhecimentos, que melhoraram suas habilidades de gestão e, ainda, que os seus funcionários puderam aprimorar sua capacitação por meio do acesso aos treinamentos oferecidos por aquela associação. Por sua vez, o Fator 5 (média $=3,68$; mediana $=4,00$ ), referente ao combate à venda direta, apresenta carga fatorial considerada elevada representando a percepção dos respondentes com relação à influência da Acomac-Guarapuava nas vendas diretas por parte dos fabricantes diretamente ao consumidor final. 
Tabela 6

Matriz de Componentes Rotacionados para os Resultados dos Relacionamentos

\begin{tabular}{|c|c|c|c|c|c|}
\hline & \multicolumn{5}{|c|}{ Fatores } \\
\hline & 1 & 2 & 3 & 4 & 5 \\
\hline Melhorou o contato da minha empresa com outras empresas do setor &, 842 & & & & \\
\hline $\begin{array}{l}\text { Hoje, possuo melhor relacionamento com os membros da Acomec do que } \\
\text { com aquelas empresas que não fazem parte dela }\end{array}$ &, 780 & & & & \\
\hline Contribuiu para o alcance dos objetivos de minha empresa & ,761 & & & & \\
\hline Diminuiu a concorrência desleal entre as empresas do setor & ,716 & & & & \\
\hline Promoveu uma maior cooperação entre os competidores &, 594 & & & & \\
\hline Permitiu acesso a linhas de crédito mais vantajosas para a minha empresa & & ,828 & & & \\
\hline Permitiu um maior crescimento da minha empresa & & ,722 & & & \\
\hline $\begin{array}{l}\text { Melhorou o desempenho financeiro da minha empresa (vendas, } \\
\text { lucratividade, faturamento) }\end{array}$ & & ,674 & & & \\
\hline $\begin{array}{l}\text { Melhorou o desempenho operacional da minha empresa } \\
\text { (qualidade/quantidade dos produtos comercializados, introdução de novos } \\
\text { produtos, melhorias dos processos) }\end{array}$ & & 626 & & & \\
\hline $\begin{array}{l}\text { Permitiu que a minha empresa tivesse um melhor desempenho em } \\
\text { comparação às outras empresas não participantes da Acomac }\end{array}$ & &, 558 & & & \\
\hline Melhorou o relacionamento da minha empresa com os fornecedores & & & ,908 & & \\
\hline Permitiu o contato da minha empresa com novos fornecedores & & & ,858 & & \\
\hline $\begin{array}{l}\text { Melhorei a capacitação de meus funcionários com a participação nos } \\
\text { treinamentos, palestras e cursos oferecidos pela Acomac }\end{array}$ & & & & ,863 & \\
\hline $\begin{array}{l}\text { Obtive acesso a novos conhecimentos e, assim, melhorei as minhas } \\
\text { habilidades de gestão }\end{array}$ & & & & ,776 & \\
\hline $\begin{array}{l}\text { Diminuiu a venda direta, sem critérios, por parte da indústria na região de } \\
\text { atuação da Acomac }\end{array}$ & & & & & 880 \\
\hline Variância Explicada & $22,9 \%$ & $18,6 \%$ & $14,5 \%$ & $12,5 \%$ & $12,1 \%$ \\
\hline Variância Acumulada & $22,9 \%$ & $41,5 \%$ & $56 \%$ & $68,5 \%$ & $80,7 \%$ \\
\hline Alfa de Cronbach &, 857 &, 848 &, 800 & 637 & - \\
\hline
\end{tabular}

Utilizou-se o coeficiente de correlação rho de Spearman para analisar correlações entre os fatores facilitadores e dificultadores com os fatores de resultado. A Tabela 7 exibe correlação positiva entre o fator dificultador cooperação e competição e os seguintes fatores de resultados: relacionamentos horizontais e atingimento de objetivos; desempenho e acesso a recursos financeiros; e venda direta. Quanto ao fator facilitador forma de gestão da associação, ele apresentou correlação positiva com fator venda direta. O coeficiente de Spearman também foi utilizado para verificar possíveis correlações entre a variável satisfação com os cinco fatores de resultado. $\mathrm{O}$ teste evidenciou haver correlação positiva apenas para o fator desempenho e acesso a recursos financeiros $(\rho s=0,369$ e $p$-value $=0,025)$, isto é, quanto maior o nível de satisfação com os resultados dos relacionamentos, maior a percepção da influência positiva dos relacionamentos sobre o desempenho e acesso a recursos financeiros. 
Tabela 7

Correlação de Spearman para Fatores Facilitadores e Dificultadores e Resultados dos Relacionamentos.

\begin{tabular}{|c|c|c|c|c|c|c|c|}
\hline & & & $\begin{array}{l}\text { Relacionamentos } \\
\text { Horizontais e } \\
\text { Atingimento de } \\
\text { Objetivos }\end{array}$ & $\begin{array}{c}\text { Desempenho } \\
\text { e Acesso a } \\
\text { Recursos } \\
\text { Financeiros }\end{array}$ & $\begin{array}{c}\text { Relacionamento } \\
\text { com } \\
\text { Fornecedores }\end{array}$ & Conhecimentos & $\begin{array}{l}\text { Venda } \\
\text { Direta }\end{array}$ \\
\hline \multirow[t]{6}{*}{$\begin{array}{l}\text { Spearman's } \\
\text { rho }\end{array}$} & $\begin{array}{l}\text { Cooperação e } \\
\text { Competição }\end{array}$ & $\begin{array}{r}\text { Correlation } \\
\text { Coefficient( } \rho s)\end{array}$ & ,568 & ,369 & ,064 &,- 229 &, 451 \\
\hline & & Sig. (2-tailed) & ,000 & ,025 & ,708 & ,173 & ,005 \\
\hline & & $\mathrm{N}$ & 37 & 37 & 37 & 37 & 37 \\
\hline & $\begin{array}{l}\text { Forma de } \\
\text { Gestão da } \\
\text { Associação }\end{array}$ & $\begin{array}{r}\text { Correlation } \\
\text { Coefficient }(\rho s)\end{array}$ & ,066 &,- 002 & ,192 &,- 044 & ,439 \\
\hline & & Sig. (2-tailed) & ,698 & ,992 & ,256 & ,796 & ,007 \\
\hline & & $\mathrm{N}$ & 37 & 37 & 37 & 37 & 37 \\
\hline
\end{tabular}

\section{Análise dos Dados}

A região de abrangência da Acomac-Guarapuava é composta por 25 cidades. Destas, a cidade de Guarapuava é a de maior porte econômico e comporta 23 das 55 empresas componentes da rede. Entre outros aspectos, isso motivou que a análise considerasse as diferenças de localização das organizações. Dessa forma, com relação às características das organizações que integram a AcomacGuarapuava, constatou-se uma aparente heterogeneidade entre as empresas localizadas na cidade de Guarapuava comparativamente àquelas localizadas em outras cidades da região de abrangência da associação.

No que diz respeito aos motivadores dos relacionamentos interorganizacionais, percebe-se que estes dizem respeito à cooperação, corroborando vários estudos que tratam do tema (e.g. Galaskiewicz et al., 2004; Galaskiewicz, 1985; Oliver, 1990; Oliver \& Ebers, 1998; Schermerhorn, 1975; Schmidt \& Kochan, 1977; Whetten \& Leung, 1979). Percebe-se que no relacionamento entre as empresas do setor de materiais de construção daquela região, principalmente na cidade de Guarapuava, predominava a competição; a cooperação era praticamente inexistente. Nos termos de Bengtsson e Kock $(1999,2000)$ e Lado, Boyd e Hanlon, (1997), os relacionamentos entre elas eram caracterizados pela alta competição e baixa cooperação, fazendo com que muitas empresas iniciassem a sua participação na Acomac-Guarapuava com o objetivo de contribuir para a melhoria dessa relação cooperaçãocompetição. Ou mesmo, como classifica Franco (2007), elas estariam estabelecendo a cooperação como etapa exploratória do funcionamento da rede, mais para aproveitar as oportunidades que por questão de estratégia.

Entretanto, Whetten e Leung (1979) alertam que o desejo de cooperação por si só não explica completamente o que leva as organizações a estabelecerem relacionamentos entre si. A cooperação pode representar uma estratégia para atingir os objetivos organizacionais, devido ao seu valor instrumental. Isso não foi evidenciado claramente durante a fase qualitativa, porém a fase quantitativa da pesquisa sugere que, como afirmam Child e Faulkner (1998), a estratégia cooperativa é uma tentativa das organizações de alcançar seus objetivos, não só pela competição. Desse modo, percebe-se que os relacionamentos entre as organizações que compõem a Acomac também foram influenciados por motivadores relacionados ao desempenho da organização (financeiro e operacional), a competitividade e o alcance dos objetivos individuais, corroborando os estudos de Dyer (1996), Franco (2007), Oliver (1990) e Whetten e Leung (1979). 
De maneira mais explícita, os dados também revelam que um dos motivadores para a participação na Acomac-Guarapuava reside na melhoria do relacionamento entre as empresas do segmento varejista de materiais de construção, com o intuito de promover trocas interorganizacionais, resolver conflitos e fortalecer as empresas. Os relacionamentos interorganizacionais também são formados, quando as organizações têm dificuldades de, isoladamente, acessar recursos escassos (Galaskiewicz, 1985; Oliver, 1990; Oliver \& Ebers, 1998; Ring \& Van de Ven, 1992, 1994; Schermerhorn, 1975; Whetten \& Leung, 1979). Dessa forma, os respondentes demonstram que sua participação na Associação também foi motivada pela possibilidade de acesso a recursos escassos, como linhas de crédito mais vantajosas para a empresa e para seus clientes e, ainda, acesso a conhecimentos, o que corrobora o trabalho apresentado por Hoffmann, Molina-Morales e MartínezFernández (2008). Eles demonstraram que as empresas presentes em redes aglomeradas possuíam maior acesso a recursos que aquelas dispersas geograficamente. Esses recursos podem ser o acesso a linhas de crédito, e financiamento, pois atua como motivador em função das condições especiais que algumas instituições financeiras oferecem aos associados da Acomac e a seus clientes, desde taxas até facilidades para contratação.

Outro motivador que se apresenta com destaque diz respeito ao relacionamento com fornecedores. Nesse caso, as organizações que integram a Associação parecem ser motivadas pela possibilidade de melhoria dos contatos com os atuais fornecedores e desenvolvimento de parcerias; contato com novos fornecedores; e, principalmente, colaborar para combater a ação dos fabricantes que vendem diretamente ao consumidor final sem a intermediação do elo varejista. Esse tipo de prática é considerada prejudicial ao setor que não consegue concorrer com os fabricantes. Considerando que, na maioria das vezes, esses fornecedores também utilizam o varejo como canal de venda, as empresas desse segmento na região de Guarapuava demonstram ser, em grande parte, motivadas a participar daquela associação para colaborar no combate a esse tipo de prática dos fabricantes. Dessa forma, corrobora-se a observação de Oliver (1990) e Whetten e Leung (1979), ao considerarem que a cooperação e o poder são motivadores que interagem, quando duas ou mais organizações estabelecem relacionamentos cooperativos para exercer poder sobre uma terceira organização.

Considerando que a fase qualitativa da pesquisa evidenciou alguns pontos em que as empresas localizadas na cidade de Guarapuava se diferenciam daquelas organizações localizadas em outras cidades, procurou-se verificar possíveis diferenças estatisticamente significativas entre elas nos motivadores dos relacionamentos. Desse modo, percebe-se que as empresas localizadas em outras cidades são mais motivadas que aquelas de Guarapuava por aspectos como relacionamentos (contatos com empresas do setor e novos fornecedores); acesso a conhecimento; e busca de competitividade. $\mathrm{O}$ que pode explicar isso é que a rede é um repositório de conhecimento, por meio das instituições de apoio (Hoffmann et al., 2008), por exemplo, ou mesmo por meio da interação das empresas (Verschoore \& Balestrin, 2008); por estarem isoladas, as empresas não teriam o mesmo acesso ao conhecimento.

Quanto aos dificultadores, nota-se que tanto a formação quanto a manutenção foram afetadas por aspectos relacionados à intensidade de cooperação e competição nos relacionamentos. De acordo com Candido e Abreu (2004), um dos principais fatores críticos para o sucesso das redes interorganizacionais de cooperação diz respeito à familiarização dos participantes com os conceitos e vantagens dessa forma de atuação. Por ocasião da formação da Acomac houve grande esforço por parte de um grupo de empresários do setor em conscientizar os demais sobre a importância da participação na rede, pois os respondentes relatam que a maioria dos empresários não tinha consciência dos benefícios que poderiam ser conseguidos pela união em torno de uma associação. $\mathrm{Ou}$ seja, seria o que Franco (2007) chamou de processo de cooperação improvisado, cujos participantes não necessariamente fizeram um planejamento para tomar parte na rede.

No que diz respeito à cooperação, a literatura tem destacado que a confiança é um dos fatores mais citados, sendo considerada como pré-requisito da cooperação (Hakansson et al., 1992; Hoffmann \& Schlosser, 2001). Nesse sentido, os respondentes relataram várias situações em que os demais concorrentes se comportaram de maneira oportunista, de modo que tais acontecimentos afetam negativamente a confiança entre os empresários do setor. 
Percebe-se, por meio dos dados qualitativos que a baixa intensidade de cooperação está mais presente entre as organizações localizadas na cidade de Guarapuava. Nas entrevistas realizadas com os respondentes de outras cidades, notou-se que os fatores cooperação e competição não se apresentaram de forma tão intensa como dificultador. Além disso, os respondentes citaram algumas práticas de cooperação entre aquelas empresas não encontradas entre suas congêneres de Guarapuava.

A literatura sugere que a dinâmica existente nas redes interorganizacionais é resultante de uma série de aspectos que reúnem em uma mesma rede de relacionamento, cooperação e competição. Desse modo, se assume o pressuposto de que o estabelecimento de relacionamentos cooperativos influencia o comportamento competitivo das organizações (Gimeno, 2004; Gnyawali \& Madhavan, 2001). Entretanto, quanto aos resultados referentes à melhoria dos relacionamentos entre as empresas do setor, os dados qualitativos e quantitativos convergem, evidenciando que houve pouca influência da associação no comportamento das empresas do setor, em termos de cooperação e competição. Nesse sentido, os respondentes parecem perceber que os conflitos continuam ocorrendo, pois muitas empresas ainda agem de maneira prejudicial aos demais associados e que as trocas interorganizacionais (informações, conhecimentos, experiências e compartilhamento de problemas comuns) entre aquelas empresas, não têm ocorrido da maneira que esperavam. Há de se considerar as palavras de Brusco (1993), que indicou que o relacionamento social anterior facilita a construção das redes. Como se nota, o relacionamento anterior se restringia à competição e talvez as empresas ainda não tenham vivenciado os resultados da cooperação, ou como diria Franco (2007), a cooperação entre eles ainda é improvisada.

Com relação ao acesso a recursos, os dados parecem corroborar o estudo de Balestrin e Vargas (2004), ao evidenciar que a Associação conseguiu influenciar positivamente o acesso a novos conhecimentos e a linhas de crédito oferecidas pelas instituições financeiras àquelas associadas à rede. De modo geral, como apontam Hoffmann, Molina-Morales e Martínez-Fernandes (2007), esse é o papel que as instituições de suporte devem ter para a geração de competitividade na rede, isto é, internalizar conhecimentos oriundos extrarrede e atender à rede com os serviços conectados à sua atividade fim.

A respeito do relacionamento com fornecedores, percebe-se que os principais esforços da Associação são no sentido de combater a venda direta ao consumidor final por parte dos fabricantes, por meio do estabelecimento de critérios para a venda direta. No entanto, não fica claro o impacto da Associação nesse sentido. Alguns respondentes percebem que essa ameaça diminuiu com as ações da Acomac; outros não percebem nenhuma mudança nesse sentido. Um ponto de convergência que se extrai dos dados é que a venda direta ainda existe e continua prejudicando o setor. $\mathrm{O}$ fato de a Associação estabelecer compras conjuntas aumenta seu poder de mercado. Contudo, ao que parece o mercado possui grande número de fornecedores, o que dificulta uma ação mais contundente por parte da rede.

Considerando a influência da associação sobre o desempenho organizacional e competitividade, enquanto capacidade individual das empresas, por meio dos dados qualitativos percebe-se que alguns respondentes não sentem que a associação teve algum tipo de influência sobre o seu desempenho organizacional e competitividade, pois afirmam que, se a associação não existisse, talvez esses indicadores permanecessem inalterados. Por outro lado, alguns respondentes veem que as ações da Acomac-Guarapuava estão impactando, mesmo que indiretamente, o desempenho e a competitividade da empresa. Avaliam também que alguns associados não têm a capacidade de perceber esse tipo de benefício. Já os dados quantitativos parecem esclarecer melhor que a maioria dos participantes da pesquisa não considera que a sua participação naquela associação tem resultado em melhoria do seu desempenho e competitividade. Esse é aspecto bastante controvertido, considerando que o acesso a recursos competitivos, como já ressaltado, leva a que se alcance maior competitividade, principalmente se esse recurso é o conhecimento (Hoffmann et al., 2008). Em outras palavras, parece mais clara a falta de percepção dos resultados do que os resultados propriamente ditos.

De maneira geral, identifica-se que a Acomac-Guarapuava não conseguiu atingir os seus objetivos e atender às expectativas dos associados da forma que se imaginava. Como se observa na 
literatura pertinente ao tema, os resultados dos relacionamentos podem estar relacionados à cooperação e competição entre as organizações que integram os relacionamentos $(e$. $g$. Bengtsson \& Kock, 1999; Candido \& Abreu, 2004; Lado et al., 1997). Os dados indicam que o fato de as ações da Associação não estar produzindo os efeitos esperados pode estar relacionado a pouca cooperação e ao predomínio da competição entre os seus integrantes, principalmente entre as organizações localizadas na cidade de Guarapuava. Essa relação torna-se mais evidente, quando se leva em conta que, durante a fase quantitativa, foram identificadas correlações estatisticamente positivas e significativas entre o fator dificultador cooperação e competição com fatores de resultado. Estes dizem respeito à melhoria dos relacionamentos entre as empresas do setor, consecução de objetivos, desempenho organizacional e combate à venda direta.

A falta de cooperação talvez esteja vinculada à pouca confiança, conforme se relata nos depoimentos. Nesse sentido, a confiança atua indiretamente como influenciadora dos resultados, porquanto, como defendem Zaheer, McEvily e Perrone (1998), a confiança se relaciona positivamente com o alcance dos objetivos pretendidos pelas organizações integrantes de determinado relacionamento interorganizacional.

Apesar de a Associação não estar conseguindo atingir os objetivos esperados, os respondentes parecem reconhecer que talvez resultados desse tipo demandem certo tempo, isto é, a conscientização para uma nova lógica de comportamento talvez só ocorra no longo prazo, pois a rede é relativamente nova. Destaca-se, conforme salienta Beamish (1987), que os resultados de um determinado relacionamento são positivamente afetados pelo tempo de duração dele. Dessa forma, de acordo com Ring e Van de Ven (1994), a associação ainda não atingiu o estágio de comprometimento com os relacionamentos, pois as organizações ainda não reconhecem os benefícios que poderão advir das ações de cooperação.

\section{Considerações Finais}

As últimas décadas foram marcadas pelo advento de considerável número de estudos focando os contatos entre as organizações, de forma que se tem dado especial atenção às ligações promovidas por meio das redes interorganizacionais. Entretanto, o crescimento no número desses estudos não assegura, aparentemente, um claro acúmulo de conhecimento, ou mesmo uma consolidação teórica. Pelo contrário, o aumento do número de estudos tem contribuído para uma situação marcada por uma heterogeneidade de conceitos, teorias e resultados de pesquisa. De maneira geral, os estudos que se propõem à revisão da literatura e ao estabelecimento de uma agenda de pesquisa parecem concordar com o apontamento de Nohria (1992, p. 3): "qualquer pesquisa que se proponha a compor a literatura sobre redes, perceberá de imediato a analogia entre ela e uma "floresta terminológica" na qual qualquer recém-chegado pode plantar uma árvore".

A partir do referencial teórico adotado, verificou-se que os estudos que abordam o contato entre as organizações têm devotado especial atenção aos aspectos que envolvem a formação e a manutenção dos relacionamentos interorganizacionais. No caso deste estudo, buscou-se incluir, além dos fatores motivadores, facilitadores e dificultadores, o resultado dos relacionamentos, pois este se evidencia como faceta menos explorada do tema.

Percebeu-se que a rede estabelecida entre as empresas ainda não atingiu sua maturidade, em função de seu tempo de existência e isso pode comprometer seus resultados. Assim, reforça-se a ideia de que o tempo é variável importante para a rede, pois a ele estão vinculadas outras variáveis (dependentes), como a confiança gerada, e o conhecimento acumulado.

Nesse caso específico, percebe-se que a competição ainda constrange a cooperação. Nota-se que isso foi mais perceptível entre as empresas mais aglomeradas territorialmente. Nesse caso específico, pode estar acontecendo um reforço da competição, na medida em que, como membros de uma 
associação mais aglomerada territorialmente, seus integrantes se expõem mais e, dessa forma, deixam mais visíveis suas vantagens e desvantagens competitivas. Aparentemente há duas explicações para esse fato. Primeiramente, a falta de relacionamentos anteriores que não os de competição podem estar impactando negativamente a construção da cooperação, principalmente no contexto de aglomeração territorial. Dessa forma, confirma-se aqui os achados de Brusco (1993) a respeito da construção de confiança e dos relacionamentos anteriores. Em segundo, destaca-se que as redes horizontais, como aquelas estudas por Balestrin e Vargas (2004) se pautavam em dispersão geográfica, como condição para seu estabelecimento, e a competição naquele caso também existia, mas se verificava mais tipicamente de redes versus redes.

Por outro lado, ressalta-se a capacidade da abordagem de recursos de explicar as possíveis fontes de vantagem competitiva de uma rede. Note-se que essa abordagem foi desenvolvida pensando no âmbito de microanálise, a empresa e seus recursos, ainda que Barney (1991) tenha pensado nos chamados recursos de acessos. Nas redes, que são formas híbridas de organização (Williamson, 1991), parece ser possível aplicar essa abordagem para explicar as fontes de vantagem competitiva. Nesse caso específico, um recurso existente na rede são as instituições de suporte à atividade, algo que tem sido comumente detectado, quando se trata de determinar recursos competitivos (Hoffmann et al., 2008; Molina-Morales \& Martínez-Fernández, 2010). Isso pode ser promissor, considerando que é um recurso que depende também das relações entre os indivíduos da rede, pois a Associação, em última instância, é o aspecto formal da rede, e assim representa o interesse de todas as empresas.

Este trabalho demonstra as dificuldades de se explicar fenômenos organizacionais complexos como as redes de relacionamento interorganizacionais e seus resultados. Entretanto, a análise dessa pesquisa evidencia sua validade, pois situações organizacionais complexas, nas quais existe uma multiplicidade de processos e interpretações a respeito de um mesmo fenômeno, ampliam as exigências para o desenvolvimento de conceitos, abordagens e métodos que possam contribuir para os estudos que pretendam buscar explanações a respeito destas condições organizacionais. Do ponto de vista dos construtos que se pesquisaram, evidencia-se o que não parece possível entender a cooperação sem tratar da confiança e da relação de competição existente. Do ponto de vista dos recursos da rede, não se pode desconsiderar a existência das instituições e o papel que exercem na manutenção da própria rede, até mesmo como intermediárias nos relacionamentos e na interiorização do conhecimento externo. Do ponto de vista das relações interorganizacionais, não parece ser possível seu estudo sem que se entenda também o contexto no qual se desenvolvem.

Este trabalho abre a possibilidade de que uma linha de pesquisa siga na direção de investigar outras redes com essas características. Apesar da intensa utilização das formas subjetivas para a mensuração dos resultados, há que considerar que esses tipos de medidas não podem ser apontados como substitutos das medidas objetivas, particularmente quando se trata de resultados econômicos, e esse é um limite deste trabalho, ao mesmo tempo que pode ser outra linha de pesquisa. Como este trabalho tem corte transversal, este mesmo campo pode ser explorado a partir de uma perspectiva longitudinal, buscando-se captar a dinâmica dos relacionamentos e de seus resultados. Sugere-se, ainda, a realização de estudo semelhante, abordando também empresas não pertencentes à associação com a finalidade de comparação dos resultados entre empresas participantes e não-participantes de relacionamentos cooperativos, podendo gerar evidências sobre as possíveis vantagens deste tipo de relacionamento.

Artigo recebido em 12.03.2010. Aprovado em 14.07.2010.

\section{Referências}

Aldrich, H. E. (1979). Organizations and environments. New Jersey: Prentice-Hall.

Ariño, A. (2003). Measures of strategic alliance performance: an analysis of construct validity. 
Journal of International Business Studies, 34(1), 66-79.

Balestrin, A., \& Vargas, L. M. (2004). A dimensão estratégica das redes horizontais de PMEs: teorizações e evidências. Revista de Administração Contemporânea, 8(Edição Especial), 203227.

Balestrin, A., Verschoore, J. R., \& Reyes, E., Jr. (2010). O campo de estudo sobre redes de cooperação interorganizacional no Brasil. Revista de Administração de Empresas, 14(3), 458-477.

Barney, J. B. (1991). Firm resources and sustained competitive advantage. Journal of Management, 7(1), 99-120.

Beamish, P. W. (1987). Joint ventures in LDCs: partner selection and performance. Management International Review, 27(1), 23-37.

Bengtsson, M., \& Kock, S. (1999). Cooperation and competition in relationships between competitors in business networks. The Journal of Business \& Industrial Marketing, 14(3), 178-194.

Bengtsson, M., \& Kock, S. (2000). "Coopetition" in business networks - to cooperate and compete simultaneously. Industrial Marketing Management, 29(5), 411-426. doi: 10.1016/S00198501(99)00067-X

Bisquerra, R., Sarriera, J. C., \& Martínez, F. (2004). Introdução à estatística: enfoque informático com o pacote SPSS. Porto Alegre: Artmed.

Brass, D., Galaskiewicz, J., Greve, H., \& Tsai, W. (2004). Taking stock of networks and organizations: a multilevel perspective. Academy of Management Journal, 47(6), 795-817.

Brusco, S. (1993). Pequeñas empresas y prestación de servicios reales. In F. Pyke \& W. Sergenberger (Orgs.), Los DI y las PYMEs: DI y regeneración económica local (pp. 25-37). Madrid: MSSS.

Candido, G. A., \& Abreu, A. F. (2004, setembro). Fatores críticos de sucesso no processo de formação, desenvolvimento e viabilização de redes organizacionais: um estudo exploratório. Anais do Encontro Nacional da Associação Nacional de Pós-Graduação e Pesquisa em Administração, Curitiba, PR, Brasil, 28.

Castells, M. (1999). A sociedade em rede. São Paulo: Paz e Terra.

Child, J., \& Faulkner, D. (1998). Strategies of co-operation: managing alliances, networks, and joint ventures. New York: Oxford University Press.

Cunha, C. R. (2004). A confiança nas relações interorganizacionais cooperativas: estudo múltiplo de casos em empresas de biotecnologia no Brasil. Tese de doutorado, Universidade Federal de Minas Gerais, Belo Horizonte, MG, Brasil.

Dess, G. G., \& Robinson, R. B. (1984). Measuring organizational performance in the absence of objective measures: the case of the privately-held firm and conglomerate business unit. Strategic Management Journal, 5(3), 265-273.

Dyer, J. H. (1996). Specialized supplier networks as a source of competitive advantage: evidence from the auto industry. Strategic Management Journal, 17(4), 271-291.

Eisenhardt, K. M. (1989). Building theories from case study research. The Academy of Management Review, 14(4), 532-550.

Fiedler, M., \& Welpe, I. (2010). Antecedents of cooperative commercialisation strategies of nanotechnology firms. Research Policy, 39(3), 400-410.

Flick, U. (2004). Uma introdução à pesquisa qualitativa. Porto Alegre: Bookman. 
Franco, M. J. B. (2007). Tipologia de processos de cooperação empresarial: uma investigação empírica sobre o caso português. Revista de Administração Contemporânea, 11(3), 149-176.

Fryxel, G. E., Dooley, R. S., \& Vryza, M. (2002). After the ink dries: the interaction of trust and control in U.S.-based international joint ventures. Journal of Management Studies, 39(6), 865886.

Galaskiewicz, J. (1985). Interorganizational relations. Annual Review of Sociology, 11, 281-304.

Geringer, J. M., \& Hebert, L. (1989). Control and performance of international joint ventures. Journal of International Business Studies, 20(2), 235-254.

Gimeno, J. (2004). Competition within and between networks: the contingent effect of competitive embeddedness on alliance formation. Academy of Management Journal, 47(6), 820-842.

Gnyawali, D. R., \& Madhavan, R. (2001). Cooperative networks and competitive dynamics: a structural embeddedness perspective. Academy of Management Review, 26(3), 431-445.

Godoy, A. S. (1995b). A pesquisa qualitativa e sua utilização em administração de empresas. Revista de Administração de Empresas, 35(4), 65-71.

Godoy, A. S. (1995a). Introdução à pesquisa qualitativa e suas possibilidades. Revista de Administração de Empresas, 35(2), 57-63.

Gulati, R. (1998). Alliances and networks. Strategic Management Journal, 19(4), 293-317.

Hair, J. F., Jr., Anderson, R. E., Tatham, R. L., \& Black, W. C. (2005). Análise multivariada de dados. Porto Alegre: Bookman.

Hakansson, H., \& Ford, D. (2002). How should companies interact in business networks? Journal of Business Research, 55(2), 133-139.

Hakansson, P., Kjellberg, H., \& Ludgren, A. (1992). Strategic alliances in global biotechnology. International Business Review, 2(1), 65-82.

Hall, R. (2004). Organizações: estruturas, processos e resultados. São Paulo: Prentice Hall.

Heimeriks, K. H., \& Shreiner, M. (2002, setembro). The influence of relational quality and alliance capacity on alliance performance: a conceptual framework. Annual International Conference of The Strategic Management Society, Paris, France, 22.

Hoffmann, V. E., Molina-Morales, F. X., \& Martínez-Fernández, M. T. (2007). Redes de empresas: proposta de uma tipologia para classificação aplicada na indústria de cerâmica de revestimento. Revista de Administração Contemporânea, 11(1ª Edição Especial), 103-127.

Hoffmann, V. E., Molina-Morales, F. X., \& Martínez-Fernandez, M. T. (2008). Competitividade na indústria do vestuário: uma avaliação a partir da perspectiva das redes de empresas aglomeradas territorialmente. Revista Eletrônica de Administração, 14(2). Recuperado em 6 julho, 2010, de http://read.adm.ufrgs.br/edicoes/pdf/artigo_560.pdf.

Hoffmann, W. H., \& Scholosser, R. (2001). Success factors of strategic alliances in small and medium-sized enterprises: a survey. Long Range Planning, 34(3), 357-381.

Human, S., \& Provan, K. (1997). An emergent theory of structure and outcomes in small-firm strategic manufacturing networks. Academy of Management Journal, 40(2), 368-403.

Isabella, L. A. (2002). Managing an alliance is nothing like business as usual. Organizational Dynamics, 31(1), 47-59. 
Jarillo, J. C., \& Stevenson, H. (1991). Co-operative strategies: the payoffs and the pitfalls. Long Range Planning, 24(1), 64-70.

Koza, M. P., \& Lewin, A. Y. (2000). Managing partnerships and strategic alliances: raising the odds of success. European Management Journal, 18(2), 146-151.

Lado, A. A., Boyd, N. G., \& Hanlon, S. C. (1997). Competition, cooperation, and the search for economic rents: a syncretic model. Academy of Management Review, 22(1), 110-141.

Lajara, B., Lillo, F., \& Sempere, V. (2002). Human resources management in the formulation and implementation of strategic alliances. Human Systems Management, 21(3), 205-215.

Laville, C., \& Dionne, L. A. (1999). A construção do saber: manual de metodologia da pesquisa em ciências humanas. Belo Horizonte: UFMG.

Loiola, E., \& Moura, S. (1996). Análise de redes: uma contribuição aos estudos organizacionais. In T. Fischer (Org.), Gestão contemporânea: cidades estratégicas e organizações locais (pp. 53-68). Rio de Janeiro: FGV.

Machado-da-Silva, C., \& Coser, C. (2006). Rede de relações interorganizacionais no campo organizacional de Videira-SC. Revista de Administração Contemporânea, 10(4), 9-45.

Malhotra, N. (2001). Pesquisa de marketing: uma orientação aplicada. Porto Alegre: Bookman.

Medcof, J. W. (1997). Why too many alliances end in divorce. Long Range Planning, 30(5), 718-732.

Mellat-Parast, M., \& Digman, L. A. (2008). Learning: the interface of quality management and strategic alliances. International Journal of Production Economics, 114(2), 820-829.

Molina-Morales, F. X., \& Martínez-Fernández, M. T. (2010). Social networks: effects of social capital on firm innovation. Journal of Small Business Management, 48(2), 258-279.

Nohria, N. (1992). Is a network perspective a useful way of studying organizations? In N. Nohria \& R. G. Eccles (Eds.), Networks and organizations: structure, form and action (pp. 1-22). Boston: Harvard Business School Press.

Oliver, C. (1990). Determinants of interorganizational relationships: integration and future directions. Academy of Management Review, 15(12), 241-265.

Oliver, A., \& Ebers, M. (1998). Networking network studies: analysis of conceptual configurations in the study of inter-organizational relationships. Organization Studies, 19(4), 459-583.

Ottone, S., \& Ponzano, F. (2010). Competition and cooperation in markets. The experimental case of a winner-take-all setting. Journal of Socio-Economics, 39(2), 163-170.

Papadopoulos, A., Cimon, Y., \& Hébert, L. (2008). Asymmetry, heterogeneity and inter-firm relationships: organizing the theoretical landscape. International Journal of Organizational Analysis, 16(2), 152-165.

Park, S. H., \& Jungson, G. R. (2001). Interfirm rivalry and managerial complexity: a conceptual framework of alliance failure. Organization Science, 12(1), 37-53.

Parkhe, A. (1993). Strategic alliance structuring: a game theoretic and transaction cost examination of interfirm cooperation. Academy of Management Journal, 36(4), 794-829.

Pereira, B. A. D. (2005, setembro). Identificação dos fatores determinantes do desempenho das empresas inseridas em redes horizontais. Anais do Encontro Nacional da Associação Nacional de Pós-Graduação e Pesquisa em Administração, Brasília, DF, Brasil, 29. 
Provan, K. G., \& Milward, H. B. (1995). A preliminary theory of interorganizational network effectiveness: a comparative study of four community mental health systems. Administrative Science Quarterly, 40(1), 1-33.

Reinl, L., \& Kelliher, F. (2010). Cooperative micro-firm strategies: leveraging resources through learning networks. International Journal of Entrepreneurship and Innovation, 11(2), 141-158.

Richardson, J. (1989). Pesquisa social: métodos e técnicas. São Paulo: Atlas.

Ring, P. S., \& Van de Ven, A. H. (1992). Structuring cooperative relationships between organizations. Strategic Management Journal, 13(7), 483-498.

Ring, P. S., \& Van de Ven, A. H. (1994). Developmental process of cooperative interorganizational relationships. Academy of Management Review, 19(1), 90-118.

Schermerhorn, J. R. (1975). Determinants of interorganizational cooperation. Academy of Management Journal, 18(4), 846-856.

Schmidt, S. M., \& Kochan, T. A. (1977). Interorganizational relationships: patterns and motivations. Administrative Science Quarterly, 22(2), 220-234.

Thoben, K. D., \& Jagdev, H. S. (2001). Typological issues in enterprise networks. Production Planning and Control, 12(5), 421-436.

Verschoore, J. R., \& Balestrin, A. (2008). Fatores relevantes para o estabelecimento de redes de cooperaçăo entre empresas do Rio Grande do Sul. Revista de Administração de Empresas, 12(4), 1043-1069.

Wegner, D., \& Dahmer, L. V. (2004, agosto). Ferramenta para avaliação de desempenho em redes de empresas: uma proposta metodológica. Anais do Seminário de Administração FEA/USP, São Paulo, SP, Brasil, 7.

Whetten, D. A., \& Leung, T. K. (1979). The instrumental value of interorganizational relations: antecedents and consequences of linkage formation. Academy of Management Journal, 22(2), 325-344.

Williamson, O. E. (1991). Comparative economic organization: the analysis of discrete structural alternatives. Administrative Science Quarterly, 36(2), 269-296.

Yan, A., \& Gray, B. (1994). Bargaining power, management control, and performance in United States-China joint ventures: a comparative case study. Academy of Management Journal, 37(6), 1478-1517.

Zaheer, A., McEvily, B., \& Perrone, V. (1998). Does trust matter? Exploring the effects of interorganizational and interpersonal trust on performance. Organization Science, 9(2), 141159. 